\title{
Food as a daily art: ideas for its use as a method in development practice
}

\author{
L. Jamila Haider ${ }^{1}$ and Frederik J. W. van Oudenhoven
}

\begin{abstract}
Food is the only art form that is also a basic need. It requires knowledge and labor for cultivation and cooking and offers a space where tastes, hospitality, and other cultural values are expressed and created. As a daily practice in agricultural societies, food is a holistic concept that incorporates ideas of health, spirituality, community, technology, and trade, and connects the most marginalized with the most powerful. Conventional international development aid is dominated by a limited number of relatively narrow ideas informed by scientific processes: progress, economic growth, market development, and agricultural production. Such ideas are often at odds with endogenous ideas about development and often work against biological and cultural diversity. Here, we reflect on our experiences documenting the food culture of the Pamiri people of Afghanistan and Tajikistan. We trace the trajectory of ideas about development, local and foreign, and explore how at different stages in those trajectories, the qualities of food can help promote local perspectives, challenge dominant power relationships, and challenge scientific practices to incorporate these perspectives better. We show how, as a method and a daily art form, food helps nurture an "ecology of ideas" in which traditional knowledge and science can come together to create locally meaningful solutions toward development and sustainability.
\end{abstract}

Key Words: Afghanistan; agricultural biodiversity; daily art; development; food; ideas; Pamir Mountains; power; seeds; Tajikistan

\section{INTRODUCTION}

Ideas seem to happen to us, like the flashing light bulb in a cartoon or Archimedes lowering himself into the water of his bathtub. First the idea is not there. Then, spontaneously, it is. Or is it?

To understand how ideas come to be and, particularly, how they take root in people's minds and in the collective mind of societies, it is not enough to locate where they began. In a sense, Foucault (1977) would say, origins are irrelevant. Understanding the paths that ideas take as they evolve, and the passions, struggles, and dissensions that shape them, brings us much closer to their essence than locating their beginning. Ideas are not singular, incorruptible monuments, but networks of interactions and the powers that move them.

This may sound abstract, but it will be useful as a premise in explaining the intention behind this paper. Our aim is to explore how new ideas that exist outside the mainstream discussions about international development aid can be brought into the development narrative and influence its course. In addition, we explore how food in general, and agricultural biodiversity in particular, can help facilitate this process.

For everyone, food is a basic need. For gastronomists and agronomists, it is also an art and a science. For the purposes of this paper, we are interested less in food in its most exalted form, as it is created in the seed laboratories and the Michelin-starred restaurants of the world, but rather in its more modest, everyday form, the way it is practiced in the kitchens and on the fields of farmers in agricultural societies worldwide. It is a tacit daily practice that, while meeting that basic need of sustenance, is also the space where knowledge and culture are applied and created. Reading a landscape, preparing it for cultivation, selecting seeds, preparing food and offering it to God, spirits, family, or guests: should food viewed in this way not be awarded the same kind of reverence we bestow on top chefs and scientists? We argue that, regarded in this way, as a daily art, food has the ability to reconcile farmers' knowledge and science. It becomes a unique tool to help advance an ecologically and culturally sustainable form of development.
Examining food is not new as a method of inquiry. It has long been an important tool for anthropologists, reflective of their commitment to documenting the "everyday" (Heldke 1988, Sutton 2001). It is much less common as a tool for action-oriented research. Here, we develop both of these sides of food as a method: as a tool for learning as well as for transformation. We begin by tracing the evolution of the idea that gave rise to this paper. It is the idea of a book that set out to document, in the form of simple recipes, the rich daily food practices of the Pamiri people, an ethnic group that is native to southeastern Tajikistan and northeastern Afghanistan (Van Oudenhoven and Haider 2015). It begins with a testimony of our own blindness.

We had both been working in the Pamirs for two years. The Pamirs are the mountains that straddle the border between Tajikistan and Afghanistan, spreading also into northern Pakistan and eastern China. They are beautiful and isolated: a barren desert, if not for the small patches of irrigated land that people have created to grow food. The Pamiri people have a rich culture expressed in ancient celebrations and traditions, dance and music, and in the many hundreds of varieties of grains, pulses, and fruits that have evolved under their care. Strangely, the food we ate during those years in the Pamirs seemed to have little bearing with that agricultural wealth. All that time, the food in restaurants, along the road, and even at people's homes seemed mostly Russian influenced and greasy with foreign oil. It was not much to write home about, except for the flatbreads, gartha or non, which were wonderful.

After two years, a question dawned. Why, in a region where 153 varieties of wheat are grown, is simple white bread the only thing made with it? In a culture that is so deeply rooted in agricultural traditions, where did all the food go? It was a good question. In response, our colleagues, scientists from the Pamir Biological Institute, proudly brought us home-cooked osh (noodle soup), noshkhukhpa (dried apricot soup), komnigul (apricot pit soup), tukhp-khakhpa (cheese curd soup), and khikhtz (sweet wedding cream), all dishes made from local crops and products. It was as if a new window opened on life in these mountains. Together, we 
began to look for more foods and, in less than six months, found the names of more than 100 traditional recipes. One day, a grandmother in the village of Mun, in the Tajik valley of Ghund, told us stories about the food she once used to eat. Soon, the entire family was there listening to her, and more and more people from her community joined. When she had finished, she asked us to write down her recipes in a book so that she could leave them for her grandchildren so they would not forget. That is how the idea of a recipe book was born.

A year later, we returned to the Pamirs. We had a list of recipes and ingredients, but to our foreign minds, they made very little sense. How do you make a soup from dried apricots and flour? What is sourdough soup, and why do you prepare the head and legs of a sheep for breakfast? Travelling through the Pamirs to look for the people behind these recipes, through villages we had never been in, we arrived at people's doorsteps as complete strangers, unannounced and uninvited. "Could you perhaps cook something for us?" we would ask, "Something special," and presented the list of recipes we still did not understand. The embarrassment we felt at doing this was always swept away by an overwhelming hospitality and kindness, and that window that had opened with hesitation two years before, now let in a colorful new world of tastes, memories, and stories. Speaking about food helped us to understand more of the difficulties of Pamiri life and more of its beauty, and to see these in a light that went beyond resource scarcity or war, the themes that are usually associated with this part of the world.

These food stories are about agriculture and the landscape in which it is practiced; they are about the history of the Pamirs. Less clearly, they are also about its future: when thinking about the past in a different way (for example, through the lens of agriculture, food, or poetry instead of economics or politics), different futures begin to appear. Knowledge emerges that before seemed hidden.

This simplified genealogy of the book idea spanned five years by the time it was published, and much longer if one counts the work that Pamiris have done to cultivate and select their ancient seeds and fruit varieties. What we mean to illustrate with this example is that it is often silly to try to demarcate an idea, where and when and with whom it began. Doing so denies it its many beginnings, its many creators, the relations between them, and the intentions, passions, doubts, and labor that have given it life.

Rethinking the conversations about food that we had with farmers, mothers, elders, teachers, and children, ideas emerged that, to us, seemed very important to the future of the region. These were ideas about identity and ways of living that are truly Pamiri, and about not losing these amid the rapids of current change. Very few of these ideas were reflected in the development projects being implemented. Why were they not there?

In the remainder of this paper, we seek to find an answer to that question, and a possible remedy. Our reasoning is as follows. (1) Ideas emerge because they are needed or useful. Usefulness, however, is never objective, it is in the eye of the beholder. The beholder who wields the greatest power (in the development arena or elsewhere), therefore, has the greatest influence over whether ideas are found to be useful and become established. Ideas from actors who are less powerful become marginalized. Speaking about food is one way to shift this power. It can create a space where different beholders have equal power. (2) However, even if a space has been created in which existing power dynamics are broken down or circumvented, what if few sovereign ideas exist? Where do original ideas come from? We propose that food as a method can help to unearth ideas, old and new, that are true to a place and a people. (3) Finally, we explore ways in which ideas, once unearthed, can take root in society.

\section{PART 1: HOW DO IDEAS EMERGE?}

One simple reason that ideas emerge and become established is because they are useful. Development organizations judge and justify their actions based on how useful they are in helping to achieve their missions and targets.

Foucault (1977) makes a similar observation about the history of morality. Many historians, he says, view the development and genesis of morality as concerned mostly with utility. Norms, behaviors, and actions are morally acceptable and, therefore, become established when they serve a purpose.

Morality and utility join forces in the interventions of development organizations, which usually act on the strong moral basis of improving the human condition and the environment. In their interventions, they select the ideas and actions that are useful from this moral standpoint. The difficulty is that it is rarely easy to know what is useful or morally appropriate in any given place or context. Utility is determined in response to a problem, which is often identified by the organization itself. Project proposals and prevailing funding systems require that problems be defined in a simplified manner so that the responses to them become manageable and easy to monitor. In this process of simplification, the problems against which the utility of interventions is judged become one-liners, e.g., poverty reduction, market development, fighting hunger, climate change adaptation, which makes it easy to lose sight of the many reasons why things are done the way they are. An agricultural field, for example, if considered from the perspective of food production, may be judged on its soil nutrients, irrigation, or crop productivity, and development responses would focus there. If viewed from the perspective of market development, the typical response is to grow marketable crops. The other functions a field may have, such as health, labor, crop diversity, or links to specific foods, may be lost in the process.

More specifically, consider the Pamiri tradition of jointly cultivating grain crops and pulses, referred to in Shughni, one of the local languages, as lashak-makh (literally rye-pea; Figs. 1 and 2). Many fields are sown with a mixture of rye, barley, pea, grass pea (Lathyrus sativus), lentil, and fava bean (see Table 1 for an overview of these crops and their names in the four main local languages). To a classical agronomist, the field looks like a mess. Yields are poor, labor is high, and the scope for intensification is enormous.

A more forward-thinking agronomist or an ecologist would view this practice as an example of traditional ecological knowledge. The mixture of plants and root systems prevents erosion, the nitrogen-fixing pulses reduce the demand on the soil posed by the grain crops, and the diversity of crops grown together reduces the risk of damage from pests and diseases. That is its function. 
Table 1. Names of the most important Pamiri grains and pulses in several languages spoken in the Pamirs.

\begin{tabular}{|c|c|c|c|c|}
\hline English (Latin) name & Dari/Tajik & Shughni & Rushani & Wakhi \\
\hline Wheat (Triticum aestivum L.) & gandum & dzhindam & dzhindam & jhdim \\
\hline $\begin{array}{l}\text { Millet (Panicum miliaceum) and foxtail millet (Panicum } \\
\text { italicum L.) }\end{array}$ & arzan & pindzh & pinj & arzin/kutnokh \\
\hline Grass pea (Lathyrus sativus L.) & patak & khidziv & zadarg & krosh \\
\hline Pea (Pisum sativum L.) & mushung, mishing & makhorj & makh & shakh \\
\hline Rye (Secale cereale L.) & jowdar & lashak & lashak & lashuk \\
\hline Barley (Hordeum vulgare L.) & jow & chushch & choshch & irk \\
\hline Faba bean (Vicia faba L. var. min.) & boqilo, baghla, boqli & termakh (makh) & khash & baqla \\
\hline Chickpea (Cicer arietinum L.) & nakhud & rivand & ravand & rivand \\
\hline Lentil (Lens culinaris Med. L.) & nask/adas & sirdzh & nask & mojuk \\
\hline
\end{tabular}

Fig. 1. A field of lashak-makh (rye-pea) in the village of Gorzwinj, in the Afghan Pamiri valley of Shughnan. The Pamiri name for rye tells a story itself: lashak comes from the word ara-lashak, which means "mixed with." Rye is never grown alone, always together with other grains or pulses. This is also how it grows naturally, as a common weed supplanting wheat or barley, which are less hardy in the poor mountain soils. Vavilov (1997) noted that the Pamirs are one of the few places in Asia where rye was grown deliberately as a domesticated crop. In the rest of Afghanistan, for example, where it was not eaten, it was called gandum-dora, "a plant that infests barley or wheat". Photograph by Judith Quax.

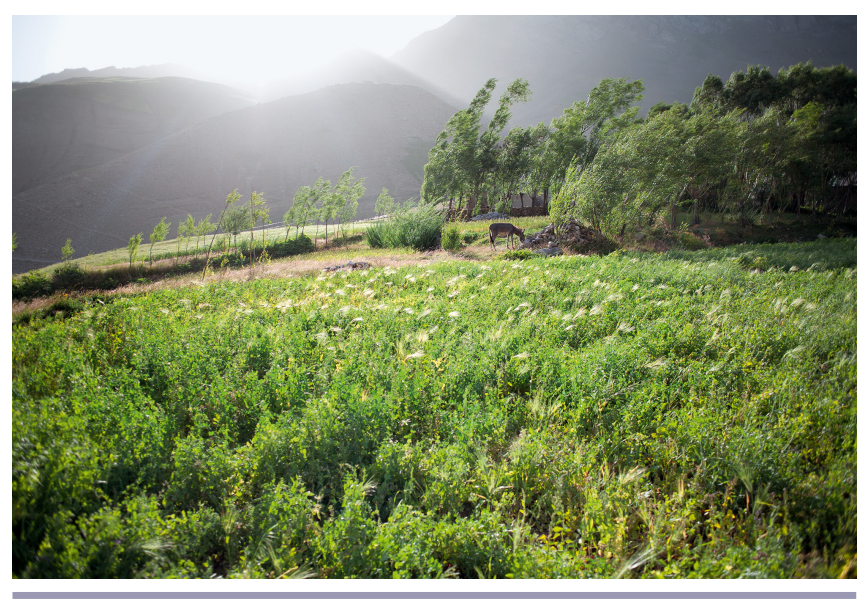

To the Pamiri cook and farmer, the function of lashak-makh is broader still. They use the harvest from these fields to make a flour called hazorza, which means "mix of a thousand." The crops are not separated, but harvested and milled together, and the hazorza flour is used to make bread or a nutritious noodle soup called $o s h$, which is rich in protein and energy and has a cooling quality when eaten while working the fields in summer. Many kinds of osh exist, made with different mixed flours that come from different combinations of crops grown at different altitudes, and many songs and poems are recited about $o s h$. The soup and the cultivation system are interlinked; the agronomic utility of the cultivation system is connected to the nutritional and cultural utility of hazorza and osh and is strengthened by it.
Fig. 2. Closeup image of the lashak-makh field in Fig. 1. Photograph by Frederik van Oudenhoven.

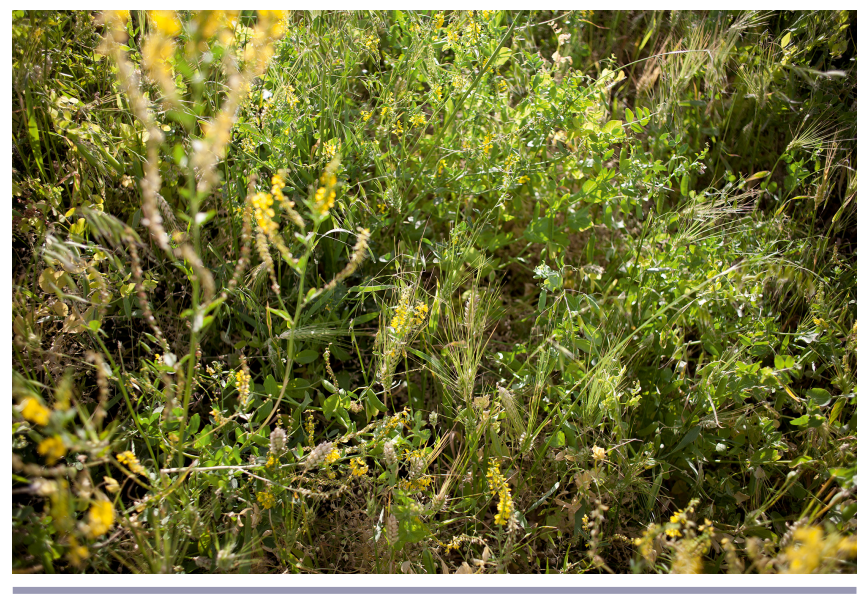

Many (agri)cultural norms and practices have functions that are not readily apparent. Is it possible to know which seemingly irrelevant knowledge, practice, or idea will be useful at some future point in time? If it is possible, who are the people to decide on which practices should remain and which ones could go? Who decides on change?

\section{Ideas need power to move them}

When different useful ideas about development compete for implementation, it is not always the most worthwhile idea that wins. Foucault (1977), when writing about the history of morality, continued to say that historians were in fact wrong to reduce the history of morality to an exclusive concern for utility. The simple explanation of utility as the genesis and persistence of ideas, he said, is blind to a very important influence: power. In our case, it is the power of development organizations.

In the Pamirs, the dynamics of power between competing ideas can be illustrated by looking at two different kinds of seeds: local seeds and ones that are introduced. Farmers in the Tajik valley of Rushan tell how, during the Tajik Civil War (1992-1997) that followed the collapse of the Soviet Union, foreign aid agencies promoted a high-yielding wheat variety to help prevent famine. The prospect of higher yields was so tempting that many farmers 
readily abandoned their old varieties, dismissing the warnings of many of their parents. Soon, however, they began to understand that they had made a poor choice: the new variety did not suit their way of cultivating wheat. It rotted when left to dry in the field and its taste was poor. By then, however, no alternatives seemed to remain: the old seeds were gone. A few farmers finally crossed the river into Afghanistan, recovered their ancestral varieties from the farmers there, and redistributed them among their communities, where they are still grown today.

High-yielding crop varieties do have clear utility in solving problems of hunger and malnutrition. In relatively controlled settings, their functionality has been proven by laboratories and research organizations; you could say that these crops have scientific authority. For development organizations, such authority is welcome because funding must often be spent on solutions that are known to work and that will help achieve targets and objectives. Science offers legitimacy to development practitioners and their ideas. It does not necessarily hold true, however, once it is in the field.

In the absence of a laboratory, where does a native seed variety gain its legitimacy? In the Pamirs, local seeds, or landraces, are often the result of several generations, and in some cases many centuries, of family farming. They have survived because they are trustworthy, tasty, and able to withstand drought or high altitudes. Their legitimacy comes from having passed through many discerning hands of neighbors, family, and friends.

In different ways, then, albeit in very different contexts, both seeds have a proven utility. The use of the introduced seed is relatively narrow (to produce high yields). In contrast, the use of most local varieties, or landraces, is generally broader: the taste of its flour to make bread or soup, the use of its straw for fodder and building materials, and its adaptation to local growing conditions and cultivation techniques.

For farmers in Rushan, it took the experiment with the highyielding wheat variety to realize that even in times of hunger, yield is not their main reason for cultivating a crop. However, although Rushani farmers learned a lesson (and had the chance to revert to their traditional varieties), such seeds continue to be distributed as a symbol of modernization and development. At times, so much effort and money are invested in their promotion that the introduction of the seeds seems to become an end in and of itself, rather than a means to relieve hunger or increase income.

\section{Locating power}

With hundreds of thousands of crop landraces in existence, adapted to settings as difficult as the Pamirs, power becomes more important than utility in explaining why a handful of highyielding seeds dominate fields (and minds) across most of the globe.

In development contexts, power often operates in subtle ways. Part of the power of a development organization lies in its position to formulate responses and development interventions in response to problems it defines. Often, this means that the problems defined by organizations correspond primarily to their own capacities or the funding they are able to obtain, and only secondarily to the reality in which the organizations work. As long as, consciously or not, problems are defined in such an external manner, solutions will also be defined externally, and identifying local sources of strength and ingenuity in a development context will remain difficult.

The purpose of these reflections is not to condemn. There is real hardship in the Pamirs, on both sides of the Afghan-Tajik border, e.g., famine, poverty, opium addiction, and child mortality, and the need for development aid is often justified. Nevertheless, however genuine the motivation, and however sensitive, community-based, or rights-based the approach to development, it remains extremely difficult to break free from an outsider's perspective of a place and one's own position of power. $\mathrm{Li}(2007: 5)$ writes that an organization's "claim to expertise in optimizing the lives of others is a claim to power." The example of the improved wheat seed shows the unintended side effects this power can have and illustrates the inevitable gap that often exists between that which is intended and attempted by development organizations and that which is accomplished.

To move the locus of power from outside organizations to people and communities who receive development assistance means to shift the responsibility of who defines problems and solutions to those very people and communities. The inevitable gap becomes less inevitable when the perspective on development is derived more from within, i.e., becomes more endogenous. Food may be one way to achieve this aim.

\section{Food as a method to shift power}

During the course of our work in the Pamirs, food proved to be a useful tool to break down or at least circumvent power relationships and help gain a deeper understanding of this place and its culture. By food, we simply mean the acts of cultivating and preparing food, of eating together and speaking and thinking about it. Anthropologists have long used food as a method for documentation. Would it also be useful for development practitioners for their work in agricultural communities? Would redefining and redirecting development efforts around food, in its broadest sense, be meaningful? We will explore a number of qualities of food that suggest that it might be.

First, food is intimate and unimposing. The vocabulary around food preparation and celebration is quite different from the jargon that we are often inclined to use when discussing food policies, conservation, or development. Such vocabulary impersonalizes something that for most farmers is very personal, and makes it difficult for them to participate in these discussions. Food touches on people's identity and history and involves those who are often excluded from the development process (mothers, grandparents, children). It is not just about cooking and eating.

Second, food provides a common vocabulary. Everyone can speak of food, it suggests no class, and does not discriminate between women or men, or donors and their beneficiaries (Douglas 1972). Food turns women into experts, and experts into fools. It has this quality, we found, because it holds a certain legitimacy as knowledge that is in use (i.e., part of common everyday practice), rather than knowledge in books or guidelines (Taylor 2004). By virtue of these qualities, food helps give words to the internal perspective needed to shift power away from outside agencies. In her feminist exploration of food as a method of inquiry, Heldke (1988) laments how conventional western philosophers have regarded women's activities such as cooking to be irrelevant and thereby rendered them invisible, and in contrast, she illuminates the philosophical significance of cooking. 
Third, although the act of using food as a method is simple, it is not simplistic. In fact, through food, people can understand global, political, or economic developments because the reverberations of those developments are felt in their food and how they obtain it, in their health, and ultimately, in their landscapes.

In many of our conversations, we were presented with so much knowledge and experience we indeed felt a little like fools: How silly did we look trying to bake bread in a traditional kitsor oven, but singeing our eyebrows instead? How much was there to learn about the proper way of grinding mulberry flour ( pikht), the best temperature of the mill stones, or the spiritually appropriate days of the week to go to the mill? Jointly preparing food, researchers together with participants, reshuffles conventional power relationships. In contrast with popular visual methods of documentation used in participatory methodologies, such as photovoice (Hergenrather et al. 2009, Berbés-Blázquez 2012), that risk objectifying knowledge (Lambek 1996; indeed, our own efforts at documenting food culture in the form of a book run the same risk), food offers an entirely different mode of production of cultural memory that emphasizes how experience and memory are created between people through experience (Sutton 2001). It is the continuous act of making food and the constant reinvention of ideas over the hearth or in the field that are sources of novelty.

\section{PART 2: WHERE DO IDEAS COME FROM IN AUTONOMOUS SPACES?}

Through listening and trying to learn about food preparation from farmers, mothers, and shepherds, our conversations created a space where we could speak as equals and where power relations, if not absent, were less apparent than if we had been there as researchers or development workers. This, we felt, was a space far away from the problems and solutions defined by the outside world of development. It was a relatively endogenous space in which people could speak freely and ideas could emerge, and often they did.

At other times, however, we were struck by people's seeming lack of endogenous ideas about their future: a lack of initiative in changing things that were not working or protecting things people were proud of. Where were those ideas and where had the energy gone for initiating change? A strange contradiction in a conversation with a wealthy shepherd in the Wakhan valley of Afghanistan suggested that we ought to look at power in yet a different, more subtle way.

The shepherd explained to us that he used to have many animals: sheep, yak, and a few Bactrian camels. Much of the herd died during a particularly severe winter, and in recent years, the shepherd had begun buying more of his food from the market. However, he sensed that those foods were causing his children to become ill and that there were many more health problems in the community than there used to be. He also felt that he was being cheated in the economic exchange at the market. Toward the end of the conversation we asked him what he wished for the future of his children. His answer was to have better access to the market.

Why did he say this? If markets make him feel cheated and are causing his children to become ill, why does he want to have better access to them? What would be the benefit? There seemed to be no logic in his response; it was as if he was not speaking for himself.
Perhaps, we thought, his own ideas seemed irrelevant to him. From the point of view of the shepherd, the ideas and solutions required to create a better future in a country that has been governed by war for as long as most people can remember must be larger than he or his community can imagine or impel. His ideas may have appeared so small as to be powerless.

The perceived smallness of ideas has to do not so much with the power of physical, political, or economic domination of one group of people over another (that kind of power can often strengthen local ideas and identity through the resistance it evokes) but rather with power at the more subtle level of ideas. Writing about post-colonial India, Spivak (1988) asked whether those who have been colonized, suppressed, dispossessed, or otherwise marginalized can still speak for themselves. The same question can be asked about ideas. Will people whose ideas have consistently been disregarded, dismissed, or outshone by other ideas (ideas with more "utility" and more power behind them) lose the ability to believe in their own ideas?

It sounds crude, but there are instances in which development has had precisely that effect. For development organizations to achieve their visions of a better world, they need buy-in from the communities with which they work. If the wishes of communities do not coincide with the work an organization is able to do, those wishes must sometimes be molded. In the same way that, in our world of hyper-consumerism, corporations seek to shape desires through marketing and advertising, development organizations gain buy-in and legitimacy through the promotion of standardized and simplified solutions (Scott 1998). In some sense, writes Li (2007:5), it is comparable to the way a government exercises power over its subjects "by educating desires and configuring habits, aspirations and beliefs. It sets conditions [so that people], following only their own self-interest, will do as they ought."

In the Pamirs, where the Afghan and Tajik governments have very little capacity and still fewer means, development organizations are in fact very near to fulfilling the role of government. Browsing through the names of their development projects, it is not difficult to see the direction in which these organizations would like the future wishes of their beneficiaries to move: there are projects for "cross-border markets," projects to develop market value chains, and projects to provide "licit and sustainable income opportunities" (AKDN 2004) and stimulate enterprise development. Even when projects have as objectives the increasing or diversification of agricultural production, fruit and vegetable processing (Roots of Peace 2008, CIDA 2011, USAID 2017), community-based tourism, or the building of community institutions, it is generally through the lens of markets, "pro-poor growth," or "unlocking the Pamirs' development potential" (FAO 2010).

Returning to the Wakhi shepherd, we ought to consider the possibility that it was the simple fact of our presence, and the development trajectory of modernization and market development we represent as foreigners, that caused the strange contradiction in his story. Even if our position was not one of power, he may have felt his conclusion was desirable in our presence. Another possibility is that his previous contact with development organizations that view markets as the main answer to poverty and hardship may have conditioned his aspirations and beliefs. 
Thus, despite being in his house, having prepared food with his wives, and having created what we thought to be a space with less power, our baggage still met his baggage. The legacy and sheer force of the modern development paradigm, and the positions we each occupied in it, weighed heavily in our interaction. It seems infuriating, for how can endogenous development occur if the ideas that obstruct it are part not only of our own minds, positions, and institutions, but also dominate the minds of the people with whom we are working?

\section{Food as a method to excavate memories and inspire ideas}

At some point in our conversation with the shepherd, we stood around a big pan of baht, and he recounted how he used to go to the pastures as a young boy. Baht is a special festive food, prepared both for the celebration of the new year in spring, and after the summer, when the women return from the pastures and the men have finished harvesting the grains that grow in fields near the village. The dish combines the fresh butter and cream from the high pastures with the best wheat from the village's fields and symbolizes the families' long-awaited reunion after summer. It is always cooked by the shepherd.

Baht is one of the most sacred, special foods made in the Pamirs; it is a dish to rejoice and give thanks to the productivity of the land and animals. While cooking the baht, the shepherd began to speak about the health of his family and to remember a time when he had control over what he exchanged through trade. $\mathrm{He}$ mentioned then that, rather than having better access to markets, he wanted more power in the market. He wanted to have a say about the things he traded and be able to trust the quality of the products like before. He then came back to the future of his children again, saying simply that he would like his children to have a normal life in which they would maintain a connection to their lands, with a livelihood to feed them. It is the same thing we would hear many more times from other parents and grandparents in the Afghan and Tajik Pamirs. The food seemed to help him go back to his own life, his youth, and his animals. It helped him dig deeper into his memory, and in that memory emerged ideas that were more of his world: a space of sovereign thought where our presence and our baggage did not act.

What is it about food that helps us get into that space? You could say that food is a tool for mental archaeology: it helps excavate memories and ideas. We look at several properties that, in our experience, give food this quality.

First, food is evocative. Its tastes and smells awaken memories and ideas, especially in places where traditional agriculture has been practiced for a long time. Even speaking and thinking about food has this effect. The food anthropologist Sutton (2001) argues that food's memory power derives in part from synesthesia, which he defines as the crossing of experiences from different senses such as taste, smell, and hearing.

Second, food is tangible and can lend that quality to things that are immaterial, such as memories. Asking elders about their favorite traditional foods often resulted in an unexpected cooking session and the proud sharing of an almost forgotten meal, embodying an almost forgotten past. Often, the associations evoked by food are positive, making it particularly suitable as a lens through which to imagine futures that are not couched in the language of hunger, destitution, or war. By always framing problems in the negative, we may find immediate solutions, but rarely will those solutions change the system that caused the problem to be born. If the problem is a lack of access to the market, then its solution is access. If poor health is the problem, the answer is more hospitals. Usually, these solutions require external help. Through food, it is easier to come to solutions that build on local possibilities.

Two simple health principles, explained to us by a Pamiri doctor, illustrate these possibilities. The first is the 2000-year-old advice by Hippocrates, "Let food be thy medicine and medicine be thy food." People in the Pamirs probably had not heard of the Greek physician, yet they created a natural diet that truly follows this idea. There is barely a traditional recipe in our book that does not also have distinct medicinal properties. The second principle comes from the writings of Avicenna, who tried as much as possible to treat his patients in their home environments, with medicines that came from there. The doctor told us how important these two ideas had become over his 40 years of practice, "We were born here. We have grown together with this place, we breathed this air, drank this water, and received our food from this soil. It makes sense to find our medicines in the things we grow or the plants we find." More than half of his Tajik Pamiri patients suffer from diet-related diseases because they are buying processed foods, he told us. Most of these diseases, he said, could be treated simply by following Hippocrates' advice or by listening to our grandparents and eating their food. And if not through food, many remedies can be found in the $>90$ medicinal plants that grow in the mountains (Fig. 3 and Table 2).

Fig. 3. A Pamiri doctor prepares a tea that has become a popular remedy against stomach parasites such as Giardia. In the tins behind him are the plants he finds in the mountains around his home and which he uses to make his natural medicines. Photograph by Jamila Haider.

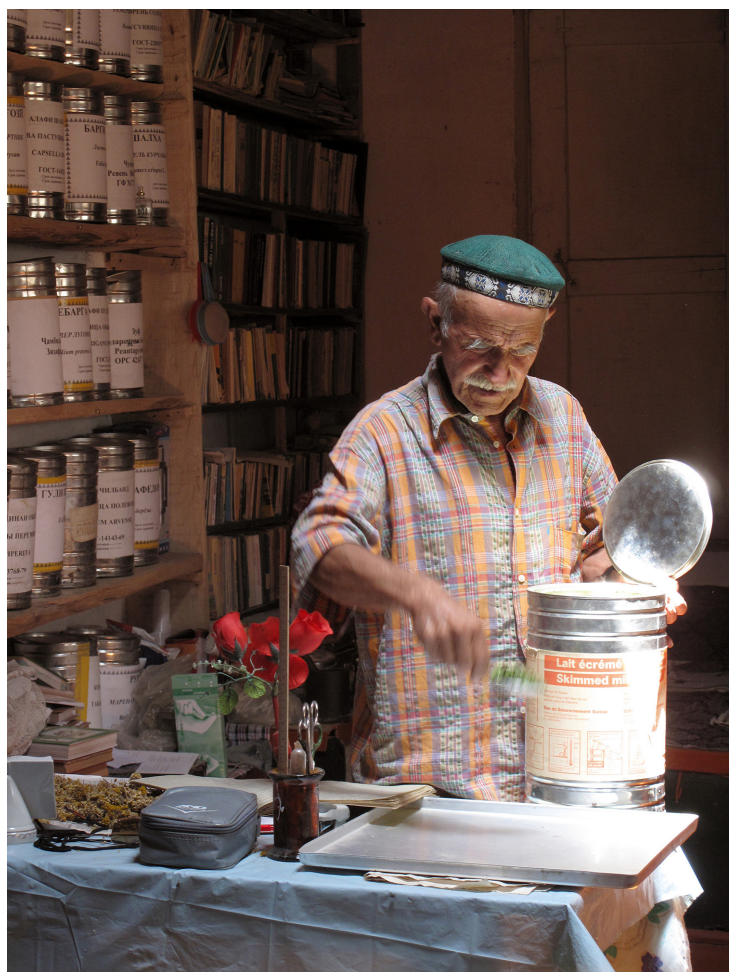


Table 2. A partial alphabetical list of illnesses and the folk remedies used to treat them in the Pamirs. For the complete list, including ailments listed from I-Z, see Van Oudenhoven and Haider (2015).

\begin{tabular}{|c|c|}
\hline Ailment & Folk remedy \\
\hline Allergies & Riv plant (Ferula grigoriewii) \\
\hline Anaemia & Sheep's liver, red and white mulberries, dried mulberry flour with cream \\
\hline Angina & Walnut hull (infused in alcohol), red mulberry (variety shatut) \\
\hline Antibiotics (natural) & Tansy (Achillea biebersteinii Afan.) \\
\hline Asthma & Ephedra (Ephedra intermedia Schrenk et C.A. Mey) and liquorice (Glycyrrhiza glabra L.) \\
\hline Bleeding, quelling of & $\begin{array}{l}\text { Common plantain leaves (Plantago major), catmint family (Nepeta glutinosa Benth.), rough pigweed (Amaranthus } \\
\text { retroflexus L.) }\end{array}$ \\
\hline $\begin{array}{l}\text { Breastfeeding, difficulty } \\
\text { with }\end{array}$ & Apricot kernel soup, walnut soup, stinging nettle leaves (Urtica dioica) \\
\hline Broken bones and bruises & Zargul (barberry family, Berberis spp.) \\
\hline Childbirth, recovery after & Rughan-kharvo (thick butter and flour-based soup), flaxseed oil porridge, zirdos soup (Achillea biebersteinii Afan.) \\
\hline Common cold and the flu & Osh noodle soup, dried apricot soup, rose hip herbal tea, jooshandeh (bitter opium tonic) \\
\hline Constipation & Apricots, walnut oil and soup \\
\hline Coughs, whooping cough & $\begin{array}{l}\text { Liquorice (Glycyrrhiza uralensis Fisch. and Glycyrrhiza glabra L.), qurboni khun (dried sacrificial blood from the sheep } \\
\text { slaughtered at Eid) }\end{array}$ \\
\hline Diarrhea & Apricot kernels \\
\hline Digestion, stimulation of & $\begin{array}{l}\text { White mulberries, mulberry flour with flaxseed, rhubarb, tanning knotweed (Polygonum coriarium (Grig.) Soják), black } \\
\text { cumin (Bunium persicum (Boiss.) B. Fedtsch.), wild carrot }\end{array}$ \\
\hline Epilepsy & Gum extracted from the stem of Ferula foetidissima, concoction of strakhm plant tips (Anaphalis virgata Thoms.) \\
\hline (Food) poisoning & Khuvdashaw (bread soaked in milk and butter), sourdough soup, yoghurt \\
\hline Goiter & Green hull of walnut fruit \\
\hline Gynecological ailments & $\begin{array}{l}\text { Decoction of young ephedra shoots (Ephedra intermedia Schrenk et C.A. Mey), decoction of rough pigweed, capers } \\
\text { (Capparis herbacea Willd.) and achillea (Achillea biebersteinii Afan.) }\end{array}$ \\
\hline Headache & Red mulberry, gum from Ferula foetidissima, purslane (Portulaca oleracea L.), sourdough soup \\
\hline Heart disease & Dried apricot soup \\
\hline High blood pressure & $\begin{array}{l}\text { Sour cheese soup (tukhp-khakhpa), apricot kernel oil with milk, raw rhubarb, black cumin tea, sourdough soup, wild } \\
\text { carrot seed }\end{array}$ \\
\hline
\end{tabular}

Third, to prepare food requires action. To make baht is to do more than make the recipe itself. Long before the cooking, the land needs to be prepared, the particular variety of red wheat selected, and the grains sown. The irrigation channels through which the water is directed to the fields must be maintained, there is weeding to be done, and threshing and milling. Higher in the mountains, in the pastures, the milking of goats, churning of butter, and reciting of songs, poems, and rituals help the process. Together, invoking these actions creates a perspective of landscape and life that is quite beautiful and full of ability, far removed from despondency.

Finally, food represents values that are fundamental to Pamiri identity. In the Pamirs, as in many other cultures, food taken from the land is considered a gift from Allah, which can barely be owned and must not be traded for profit. It should be shared and given to the weak or those who are in need.

A story we recount in our book is of a woman from Derzud, in the Tajik valley of Rushan. She recalls an incident from during the Tajik civil war (1992-1997), when the socialist economic system had collapsed and the Pamirs returned to their traditional barter economy:

I went to Khorog, the city, to see if I could exchange a small bag of mulberries I had at home. A woman from upper Roshtkhala (where it is too high to grow fruit) approachedme and asked if she could have the mulberries for her children, who were suffering from starvation. She did not have anything to give me in return, but promised that once she was able to, she would find me and give me something as payment. I did not imagine that she would be able to keep her word, but still gave her the mulberries. A few months later, I saw the woman again, and she gave me a small goat as thanks. The mulberries had helped her children survive, she told me. I was very surprised and thought how incredibly valuable that small bag of mulberries had been! I invited the woman to my house and gave her bags of mulberries and other dried fruit. I then felt happy, as I felt I hadn't done anything wrong.

In the Pamirs, as in any mountain culture where food is both sacred and scarce, sharing is as necessary as it is virtuous. The values of reciprocity, inclusiveness, hospitality, and fairness have deep roots in the ethics of the local Islamic tradition and are an important part of Pamiri culture. The idea that one should not profit from the exchange of essential goods such as food, labor, and hospitality is a central principle of the traditional system of economic exchange in the Pamirs. In the local interpretation of the Koran, selling and trading are often poorly regarded. Such principles may not be written or enforced, but one is reminded of them by well-known Pamiri expressions: Hamsoyata hamsoyayard savdo nakikht ("A neighbor never trades with a neighbor") or Hamsoya dasti soya ("Your neighbor is like a shading hand protecting you from the heat of the sun"). This is why the woman ended her story, not by saying how proud she was of her good deed, but rather that, despite having benefited from the exchange, she had remained true to her values and "hadn't done anything wrong." 
This value of communality is at sharp odds with the trend of commercialization visible in the names of Pamiri development programs listed earlier. Bread represents respect, hospitality, and generosity, and baht represents thankfulness and family, all values that people feel are slowly declining.

Food is a vessel of many things. In both the Islamic and Christian traditions, it is often the most mundane foods such as bread that are also the most holy and powerful in invoking memory (Sutton 2001). Using food as a method helps to create a space in which novel ideas emerge and can be expressed and old ideas can be excavated, dusted off, and become part of an endogenous perspective on development. The question that remains is how, once "small" local ideas emerge, they may take root and thrive alongside or in competition with more powerful ones.

\section{PART 3: HOW DO IDEAS TAKE ROOT?}

The idea that food can help in reimagining alternative ideas about development was not present at the start of our book journey, when all we intended to do was collect recipes. Although the process of describing how these recipes became stories and the stories became ideas is not simple, the conclusion, surprisingly, is. To cook food with people and to eat together from a shared dish allows us to understand ideas and solutions for rural development practice as springing from the relationships between people, their communities, and their landscape. Just as plants and animals are part of an ecological system, and seeds need to be understood in the agricultural system of which they are a part, ideas about food and the development of agricultural landscapes need to be understood in relation to, and as a result of, other ideas and the people who carry them. This way of understanding how ideas interact has been called an "ecology of ideas" (Bateson 1972).

In such an ecology, as an idea becomes established, it increasingly connects to other ideas until, eventually, the idea becomes crucial to the survival of the system as a whole. Throughout this paper, we have discussed some of the ideas that Pamiri farmers shared with us about their future: raising their children to maintain a connection to their land and traditional livelihoods, growing grains and pulses together in lashak-makh fields, and using food and local plants for medicine. In other words, they are seeking and adopting a type of development that does not destroy important local and traditional values. However, if these ideas find no soil, no socio-cultural or institutional network into which they can be incorporated and nourished, they cannot flourish and survive. Ideas are not singular entities and cannot exist as such; they need a support structure, or an ecology, of which they become a part.

Viewed from the perspective of an ecology of ideas, the reason that food has such evocative power and that phrasing ideas in the language of food may help them spread and gain relevance is because food touches on most elements that make up daily life: health, livelihood, agriculture, science, art, spirituality, and trade. The more such linkages are allowed to persist, the more these elements remain viewed as integral parts of the food system, and the greater the power of food to help new ideas connect to an existing ecology and take root.

Unfortunately, this is not usually the way scientific or development programs introduce their ideas (or their seeds). The way in which the organizations and donors behind these programs are organized requires that the building blocks of human life be compartmentalized into scientific disciplines or sectors that can be managed within the framework of projects, e.g., productivity, income generation, health, and culture, thereby severing the same linkages that make food such a holistic and overarching concept. Imagine how an improved seed variety, designed for monoculture, would fare in the colorful chaos of a field of lashak-makh (Fig. 2). It would not survive the difficult soils without a substantial dose of fertilizer or the competition from other plants without the use of herbicides. The agricultural system must change if the newly introduced seed is to succeed; it must be compartmentalized. So the seed becomes divorced from the soil and the traditional practices that connect farming and communities, such as seed saving and selection. It will no longer have its place in prayer, food, and social networks of exchange, the very things that give a local seed its relevance and enable it to adapt to changes in the environment and culture.

The same risk exists for ideas. We return one last time to the dichotomy between ideas as singular monuments and ideas as networks and interactions. Even though external ideas are part of networks as much as local ideas are, we have here pictured them as more monumental, i.e., as one-liner solutions to problems whose conception often occurred elsewhere. In many ways, they take root as a plant's taproot might: central, singular, and straight. In being monumental and more rigid, they are less able to adapt to a new home and are less sensitive to it.

In contrast, what we have called endogenous, or local, ideas are the ideas that spring from everyday processes of innovation and learning; the way a farmer learns when working her fields. Their growth may be likened to that of a rhizome (Fig. 4) in contrast to the taproot of the more defined ideas described above. Having no one source or origin, and, perhaps, no fixed goal or direction, they evolve and adapt when faced with something unknown, drawing on a reservoir of related ideas, whether technical knowledge, memories, prayer, or folklore.

Fig. 4. The rhizome of the medicinal plant Caulophyllum thalictroides (blue cohosh). Image from Lloyd and Lloyd (1884).

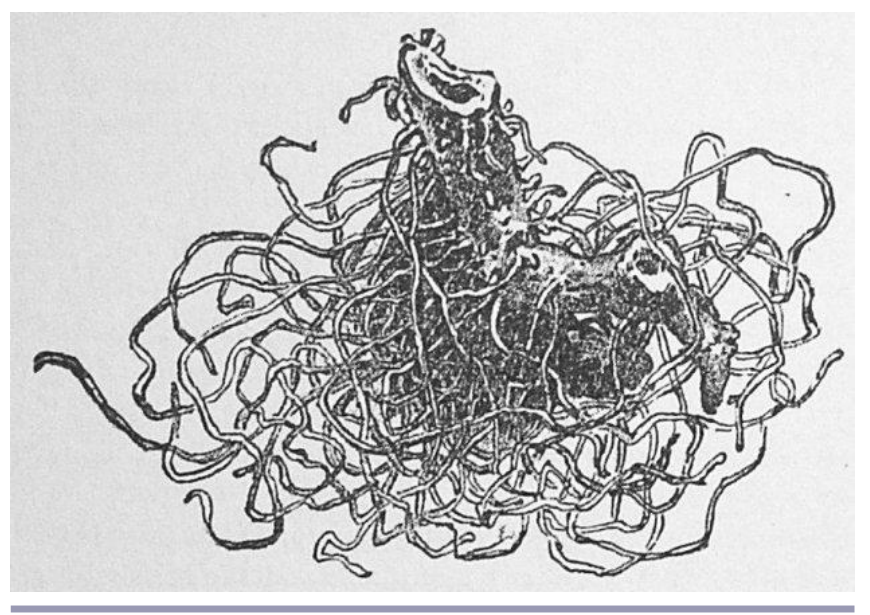


We do not argue that all local ideas are good and all external ideas are bad. Both are needed, but they need to be able to interact on a more equal level. Science has made many advances in recognizing and valuing indigenous and local knowledge (Tengö et al. 2014), but it is in facilitating this interaction of local and external ideas that scientific and development organizations still have much work to do. Nurturing an ecology of ideas goes much beyond the mostly futile and sometimes arrogant exercise of validating one system of knowledge from the point of view of another. It is also more than reserving a space for local knowledge systems in scientific discourse as an enrichment to that understanding. Real interaction requires, first of all, an attempt at seeing local knowledge systems in their entirety, recognizing that they are interwoven with the many elements of life that have contributed to its existence. Second, it means deflating the power of science to the more modest dimensions of the local ecology of ideas. And lastly, it requires the creation of spaces, whether in a kitchen, an orchard, or an office, where ideas of equal power have a fair chance to interact and come together to create locally meaningful solutions. It is in facilitating such interactions, through engagement, experimentation, and the collective interrogation of ideas, and in being modest about introduced ideas and judging them against the wisdom of ancestral knowledge present in the places where they work, that we argue scientific research and development organizations have a very positive role to play.

We return to where we began, the course the idea of our book took over the five years of its creation and the place it now takes in the ecology of ideas of the Pamirs. When the book was completed, in 2015, we returned to the Pamirs with 1700 copies: one for each community, school, and library on both sides of the Afghan-Tajik border. In a sense, the book is a simple repository of local knowledge. However, to Members of Parliament, officials, and even the Pamiri people themselves, this knowledge in written form appears to have far more authority than the same knowledge when it existed "only" in an oral tradition. An elderly man, after flipping through all of the 688 pages, laughed loudly and, in wonder, noted that it captured the knowledge that until now had only existed in his hands. Development agencies have begun to use the book in their programs, scientists have taken note, and so a dialogue between local and foreign development ideas is beginning to take place, however cautiously. At a different level, the ideas present in the book are not end points; they are alive so long as the people reading them are able to relate them to their daily lives or have (grand)parents able to rekindle that link. The transmission of recipes, medicinal preparations, and cultivation methods is an active process of enculturation (Sutton 2001) and goes hand in hand with the transmission of memories and histories and the imagination of futures.

Responses to this article can be read online at: http://www.ecologyandsociety.org/issues/responses. php/10274

\section{Acknowledgments:}

We are grateful to the Oxfam Novib-Hivos Knowledge Programme Agrobiodiversity@knowledged for commissioning an earlier version of this paper and their support throughout the writing process, in particular, Sarah Doornbos and Willy Douma. Thank you to Carl Folke for the encouragement to submit this article to the special feature, and we are grateful to The Beijer Institute of Ecological Economics for funding for open access publication. LJH and FJWO contributed equally to this article.

\section{LITERATURE CITED}

Aga Khan Development Network (AKDN). 2004. Aga Khan addresses Berlin conference on progress in Afghanistan. Press release. AKDN, Geneva, Switzerland. [online] URL: http://www. akdn.org/Content/463

Bateson, G. 1972. Steps to an ecology of mind: collected essays in anthropology, psychiatry, evolution, and epistemology. University of Chicago Press, Chicago, USA. http://dx.doi.org/10.7208/ chicago/9780226924601.001.0001

Berbés-Blázquez, M. 2012. A participatory assessment of ecosystem services and human wellbeing in rural Costa Rica using photo-voice. Environmental Management 49(4):862-875. http:// dx.doi.org/10.1007/s00267-012-9822-9

Canadian International Development Agency (CIDA). 2011. Enhancing licit livelihoods opportunities in northern Afghanistan.

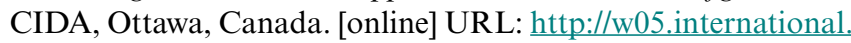
gc.ca/projectbrowser-banqueprojets/project-projet/details/a033778001

Douglas, M. 1972. Deciphering a meal. Daedalus 101(1):61-81. [online] URL: http://www.jstor.org/stable/20024058

Food and Agriculture Organization (FAO). 2010. Republic of Tajikistan: unlocking Pamirs' development potential: participatory investment planning workshop report. FAO, Rome, Italy. [online] URL: https://cashmereforum.files.wordpress.com/2010/05/workshopreport-final-eng.pdf

Foucault, M. 1977. Language, counter-memory, practice: selected essays and interviews. Cornell University Press, Ithaca, New York, USA.

Heldke, L. 1988. Recipes for theory making. Hypatia 3(2):15-30. http://dx.doi.org/10.1111/j.1527-2001.1988.tb00066.x

Hergenrather, K. C., S. D. Rhodes, C. A. Cowan, G. Bardhoshi, and S. Pula. 2009. Photovoice as community-based participatory research: a qualitative review. American Journal of Health Behavior 33(6):686-698. http://dx.doi.org/10.5993/AJHB.33.6.6

Lambek, M. 1996. The past imperfect: remembering as moral practice. In P. Antze and M. Lambek, editors. Tense past: cultural essays in trauma and memory. Routledge, Oxford, UK.

Li, T. M. 2007. The will to improve: governmentality, development, and the practice of politics. Duke University Press, Durham, North Carolina, USA. http://dx.doi.org/10.1215/9780822389781

Lloyd, J. U., and C. G. Lloyd. 1884. Drugs and medicines of North America: a publication devoted to the historical and scientific discussion of botany, pharmacy, chemistry and therapeutics of the medical plants of North America, their constituents, products and sophistications. J. U. \& C. G. Lloyd, Cincinnati, Ohio, USA. [online] URL: https://archive.org/details/b20414535

Roots of Peace. 2008. Alternative development program / North. Final report - Badakhshan fruit and nut production and marketing 
project. Roots of Peace, San Francisco, California, USA. [online] URL: http://rootsofpeace.org/wp-content/uploads/2011/09/

USAID_Alternative Development_Program-North_ROP_Final_Report. pdf

Scott, J. C. 1998. Seeing like a State: how certain schemes to improve the human condition have failed. Yale University Press, New Haven, Connecticut, USA.

Spivak, G. C. 1988. Can the subaltern speak? Pages 271-313 in C. Nelson and L. Grossberg, editors. Marxism and the interpretation of culture. University of Illinois Press, Urbana, Illinois, USA.

Sutton, D. E. 2001. Remembrance of repasts: an anthropology of food and memory. Berg, Oxford, UK. http://dx.doi. $\underline{\text { org/10.5040/9781350044883 }}$

Taylor, C. 2004. Modern social imaginaries. Duke University Press, Durham, North Carolina, USA.

Tengö, M., E. S. Brondizio, T. Elmqvist, P. Malmer, and M. Spierenburg. 2014. Connecting diverse knowledge systems for enhanced ecosystem governance: the multiple evidence base approach. Ambio 43(5):579-591. http://dx.doi.org/10.1007/ $\underline{\text { s13280-014-0501-3 }}$

United States Agency for International Development (USAID). 2017. Commercial horticulture and agricultural marketing project (CHAMP): overview. USAID, Washington, D.C., USA. [online] URL: https://www.usaid.gov/node/67201/

Van Oudenhoven, F. J. W. and J. Haider. 2015. With our own hands: a celebration of food and life in the Pamir Mountains of Afghanistan and Tajikistan. LM Publishers, Utrecht, The Netherlands.

Vavilov, N. I. 1997. Five continents. International Plant Genetic Resources Institute, Rome, Italy. [online] URL: https://www. bioversityinternational.org/fileadmin/user_upload/online library/ publications/pdfs/419.pdf 